British Journal of Nutrition (2022), 128, 2453-2463

(C) The Author(s), 2022. Published by Cambridge University Press on behalf of The Nutrition Society. This is an Open Access article, distributed under the terms of the Creative Commons Attribution licence (http://creativecommons.org/licenses/by/4.0/), which permits unrestricted re-use, distribution and reproduction, provided the original article is properly cited.

\title{
Animal-source foods as a suitable complementary food for improved physical growth in 6 to 24-month-old children in low- and middle-income countries: a systematic review and meta-analysis of randomised controlled trials
}

\author{
Hannah Asare ${ }^{1 *}$, Alice Rosi ${ }^{2}$, Mieke Faber ${ }^{1,3} \dagger$, Cornelius M. Smuts ${ }^{1} \dagger$ and Cristian Ricci ${ }^{4} \dagger$ \\ ${ }^{1}$ Centre of Excellence for Nutrition, North-West University, Potchefstroom, South Africa \\ ${ }^{2}$ Human Nutrition Unit, Department of Food and Drugs, University of Parma, Parma, Italy \\ ${ }^{3}$ Non-Communicable Diseases Research Unit, South African Medical Research Council, Tygerberg, South Africa \\ ${ }^{4}$ Africa Unit for Transdisciplinary Health Research (AUTHeR), North-West University, Potchefstroom, South Africa \\ (Submitted 13 March 2021 - Final revision received 4 January 2022 - Accepted 21 January 2022 - First published online 3 February 2022)
}

\section{Abstract}

Although animal-source foods are suitable complementary food for child growth in low- and middle-income countries (LMICs), their efficacy is still under discussion. This systematic review and meta-analysis was done to investigate the suitability of animal-source foods intake on child physical growth in LMICs. A systematic literature search was done using electronic databases and scanning the reference list of included studies, previous meta-analysis and systematic reviews. Paper selection was based on the PICO (ST) criteria. Papers were selected if based on 6 to 24-month-old children, if they were randomised controlled trials evaluating the effect of complementary animal-based food supplementation of any natural origin, if reporting at least a measure of body size and published after 2000. The PRISMA guidelines for reporting systematic review was followed in the paper selection. Fourteen papers were included in the systematic review and eight were considered for the meta-analysis. Animal-based food supplementation resulted in a higher length-for-age LAZ and weight-for-age (WAZ) $Z$-scores compared with the control group with random effect size of 0.15 (95\% CI 0.02, 0.27) and 0.20 (95\% CI 0.03, 0.36), respectively. Results were confirmed after influence analyses, and publication bias resulted as negligible. An increased effect on LAZ and WAZ was observed when the food supplementation was based on egg with effect size of $0.31(95 \% \mathrm{CI}=-0.03,0.64)$ and $0.36(95 \% \mathrm{CI}=-0.03,0.75)$, respectively. Animal-source foods are a suitable complementary food to improve growth in 6 to 24 -month-old children in LMICs.

Key words: Animal-source foods: Growth: Body measures: 6 to 24-month-old children

Child undernutrition, a condition due to energy and/or to macroand micronutrient deficiencies, is characterised by stunting, underweight, wasting, and vitamin and mineral deficiencies ${ }^{(1)}$. Worldwide, an estimated 144 million children under 5 years are stunted, 101 million are underweight and 47 million are wasted $^{(2,3)}$. The consequences of child undernutrition can be both short and long term, such as morbidities, mortality, cognitive, motor and language impairment, decreased adult stature, poor school performance, and decreased learning capacity resulting in decreased future earning potential ${ }^{(2)}$. The direct and indirect cost of child undernutrition to an individual, family, nation and the world cannot be overlooked. In 2013, the cost of child undernutrition, including micronutrient deficiencies, was estimated at US\$1.4 to 2.1 trillion/year, equivalent to 2 to $3 \%$ of the global gross domestic product ${ }^{(4)}$. Despite the negative consequences of child undernutrition, most of the root causes such as food insecurity, inappropriate child feeding practices and insufficient intake of energy content, vitamins and minerals are preventable ${ }^{(4)}$. The pathway to prevention includes but not limited to the provision of adequate nutritious, diverse and safe diets to children, especially those who are the most vulnerable. It is globally acknowledged that this can be achieved during the complementary feeding phase, which is usually between 6 and 24 months of age. This phase starts when breast milk alone is no longer enough to meet the nutritional requirements of growing children, and thus other foods and liquids need to be

Abbreviations: BMIZ, BMI-for-age; HCAZ, head circumference-for-age; LAZ, length-for-age Z-score; LMICs, low- and middle-income countries; WAZ, weightfor-age Z-score.

* Corresponding author: Ms H. Asare, email akuadodoo83@gmail.com

$\dagger$ These authors contributed equally to this work 
introduced while breast-feeding continues ${ }^{(5,6)}$. Notably, meeting the nutritional requirements of this age group is a challenge in most low- and middle-income countries (LMICs), communities, populations, and low-income households due to lack of resources to access nutritious food. Moreover, in these resourcelimited settings and households, the complementary foods are often introduced too early or too late, given in smaller quantity, not given frequently enough and are of poor nutritional quality $^{(6-9)}$. A diet of poor nutritional quality has little variety in the food consumed and is low in micronutrients, particularly for $\mathrm{Fe}, \mathrm{Zn}$, vitamin $\mathrm{A}$, iodine and essential fatty acids. It has been shown that the lack of dietary diversity and the poor quality of complementary foods in the short- and long-term impact negatively on the nutritional status and growth of children ${ }^{(10,11)}$.

Animal-source foods such as eggs, meat, fish and dairy have been shown to be a suitable complementary food to be added to the usual diets of growing children, especially those in LMICs, communities, populations and low-income households who are vulnerable to undernutrition, because they have the potential to improve their nutritional and health status ${ }^{(12-15)}$. Foods from animal origin such as meat, eggs, fish and milk are known to be rich in nutrients such as protein, essential fats such as $n-6$ and $n-3$ fatty acids, vitamin $\mathrm{A}, \mathrm{Fe}, \mathrm{Zn}$, choline and vitamin $\mathrm{B}_{12}$ needed to promote growth, motor and cognitive development of infants and young children, particularly those susceptible to undernutrition $^{(12-14,16)}$. Despite the potential nutritional benefits of animal-source foods, it has been reported that children, particularly those in LMICs, communities, populations and low-income households are hardly given foods such as meat, eggs, fish and milk ${ }^{(15)}$. It should be noted though that previous studies from high-income countries advise against the introduction of cow's milk in the main drinks of infants before 12 months of age due to it being a poor source of Fe; however, it was suggested that it can be added to complementary foods in small quantity ${ }^{(17)}$. Hence, there is the need for high-quality studies that seeks to investigate the suitability of animal-based foods during complementary feeding on the growth, macro- and micronutrient status of children from high-income countries and resource-rich environment who may not have access to supplementation, fortified foods and/or drinks as well as well-planned vegan diet diets due to an increasing prevalence of the practice of vegetarian diets among caregivers ${ }^{(18-22)}$. Against this background, previous and recent literature have shown that infants and young children, especially those from LMICs, communities, populations and low-income households are at high risk of growth faltering, macro- and micronutrient deficiencies due to inadequate consumption of animal-based protein-rich foods ${ }^{(17,23-25)}$

Previously, protein deficiency was considered the main determinant of undernutrition in resource-limited settings ${ }^{(26)}$. This therefore led to the promotion of the provision of adequate energy content in the diet of children to improve their dietary protein intake ${ }^{(13)}$. Proteins are needed by the body for building and maintenance of bones, muscles and skin. Dietary proteins act by promoting high circulating levels of insulin, insulin-like growth factor 1 and free triiodothyronine to stimulate bone and tissue growth ${ }^{(27)}$. Additionally, the amino acids from dietary proteins play a role in the promotion of the synthesis of mechanistic target of rapamycin complex 1 (mTORC1), a catalytic protein that regulates cellular growth and differentiation. This catalytic protein acts on growth plates to enhance endochondral ossification, the process of bone formation. However, mTORC1 cannot be synthesised directly by the human body and so must be obtained from foods, of which the best food sources are animal-source foods such as eggs, fish, milk and meat ${ }^{(13,26)}$.

Thus, it is well acknowledged that the inclusion of animalsource foods to the usual complementary diets of growing children, especially those in LMICs, communities, populations and low-income households have the potential to optimise their nutritional status and thus help to alleviate child undernutrition $^{(12,13)}$. Nevertheless, there is still dearth of evidence on the extent to which the addition of animal-source foods in the complementary diets of infants and young children, especially those in LMICs, communities, populations and lowincome households enhance their growth and development. A recent Cochrane review published in $2019^{(14)}$ reported insufficient evidence to suggest that animal-source foods are effective complementary foods for growth and development in children aged 6 to 59 months from LMICs. Notably, the Cochrane review included only five studies ${ }^{(28-32)}$ in their quantitative synthesis. Additionally, recent feeding trials have focused on the effectiveness of daily consumption of an egg to improve child growth and development in LMICs, with discrepancies in linear growth outcomes $^{(30,33,34)}$. Moreover, egg interventions are of great interest due to the cultural and religious beliefs associated with egg intake $^{(35)}$, especially in resource-limited settings. Recently, a systematic review on the effect of animal-based food on growth on 6 to 60 months children from LMICs pointed out a large heterogeneity among studies. This investigation resulted in the recommendation that subsequent studies should differentiate age groups. Another recommendation from this systematic review was that researchers should focus on the consistency in the definition and quantification of treatment and outcomes ${ }^{(36)}$.

Therefore, the primary objective of this systematic review and meta-analysis was to investigate whether the intake of animalsource foods accelerated the physical growth of children from LMICs, communities, populations and low-income households by using data from randomised controlled trials. Due to the availability of heterogeneous studies, we focused on previous evidence evaluating if animal-based food was a suitable complementary food that may help increase the $Z$-score of body size measures in children aged 6 to 24 months. The secondary objective was to ascertain the suitability of giving eggs on linear growth of children in LMIC, communities, populations and low-income household.

\section{Methods}

\section{Eligibility criteria of included studies}

Papers were selected according to the extended PICO (ST) principles. Notably, the target population (Population) was defined as children in the age range of 6 to 24 months. Papers were selected based on studies evaluating the effect of complementary animal-based food consumption of any natural origin 
Table 1. PICO (ST) criteria (participants, interventions, comparisons, outcomes and study design) used to define the research question

PICO (ST)

elements

Participants Infants in the age range of 6 to 24 months

Interventions Complementary animal-based food consumption of any natural origin

Comparisons No intervention or any other non-animal-based food supplementation

Outcomes Measure of body size in the form of age- and sex-specific Z-score

Study design Randomised controlled trials

Timing Papers published after 1 January 2000

(Intervention) with respect to no intervention or any other non-animal-based food supplementation (Comparison). We considered only studies reporting at least one measure of body size (Outcome). We included only randomised controlled trials (Study design) and was limited to papers published between 1 January 2000 and 1 August 2020 (Time) in peer-reviewed Academic Journals. We limited the literature search to papers published after 2000 to reduce methodological heterogeneity and optimise the study ${ }^{(37,38)}$. The Human Research Ethics Committee of the North-West University (NWU00281-21-A1) approved this study.

\section{Data sources and literature search}

Medical Subject Headings (MeSH) and key terms were used to define a two-level hierarchical search string defined according to the above PICO (ST) inclusion criteria. Specifically, several $\mathrm{MeSH}$ items was defined for any of the above PICO (ST) elements, and the keywords search were linked by the OR/AND operators. Afterwards, several MeSH searched items, at least one for any PICO (ST) domain, were linked to the elements with the NOT operator to avoid the over selection of unwanted paper. Details of literature search strings are reported as a supplemental material, and Table 1 reports the PICO (ST) strategy. The literature search was conducted by searching electronic databases (MEDLINE, COCHRANE, EMBASE, CINAHL and Web of Science) and scanning the reference list of included studies, previous meta-analysis and systematic reviews.

\section{Study selection and risk of bias assessment}

Study selection was conducted independently by two investigators (HA and CR) according to the Preferred Reporting Items of Systematic reviews and Meta-Analysis (PRISMA) guidelines (39). Firstly, potential studies of interest were selected according to their titles and abstracts. Afterwards, the full text of all the potentially relevant studies were proofread for final eligibility. Papers reporting the effect of animal-source food supplementation $v$. no supplementation or non-animal-source supplementation on the length-for-age $Z$-score (LAZ), weight-for-age $Z$-score (WAZ), weight-for-length (WLZ), head circumference-for-age (HCAZ) and BMI-for-age (BMIZ) were further selected for the metaanalyses as secondary outcome measurements.

Two investigators (HA and CR) independently assessed the risk of bias according to the Cochrane Handbook for Systematic
Review of Interventions. A qualitative three-level score (high, some concerns and low) was then attributed. Briefly, five different types of bias were scored. The use of a random sequence generation and allocation concealment were scored in two different sub-items to evaluate the selection bias. Performance bias (blinding of participants and operators), detection bias (blinding of outcome assessed), attrition bias (incomplete outcome data) and reporting bias (selective reporting of results) were coded by one item each. Any disagreements regarding study selection and risk of bias assessment were resolved by consensus. If no agreement was reached, a third author (CMS) was consulted to discuss and deliberate on the discrepancy or issue and to reach an agreement by all involved.

\section{Statistical analyses}

The meta-analysis for this study was based on the overall effect of the food consumption on stunting (primary outcome), underweight and wasting (secondary outcome). The values used were based on the reported difference between the treatment and the control group at the end of the study in the included papers. Specifically, unless already reported, treatment to control difference was computed as the difference between the mean $Z$-scores of the outcome indicator at the end of the study. The standard error was computed as the pooled standard error, $s^{2}{ }_{p}=\left(n_{1}-1\right) s^{2}{ }_{1}+\left(n_{2}-1\right) s^{2}{ }_{2} / n_{1}+n_{2}-2$, where the subscripts 1 and 2 represent the two groups under evaluation while $n$ and $s$ portray the sample size and standard deviation by group. If adjusted and unadjusted effects were reported by the same study, the most adjusted outcome was used, more precisely, baseline adjusted marginal means were chosen over the unadjusted raw post-line means by group. The main meta-analysis was conducted as a meta-analysis of the above-described post-line mean differences between treatments and controls using a random effect model with inverse variance study weights computed as $\mathrm{w}_{\mathrm{i}}=1 /\left(\mathrm{s}_{\mathrm{i}}^{2}+t^{2}\right)$, where $\mathrm{s}_{\mathrm{i}}^{2}$ was the variance estimate from the $\mathrm{i}$-th study, and $t^{2}$ was the overall variance. The fix effect estimate was also reported as a secondary analysis.

Heterogeneity between studies was evaluated using the Cochrane Q test and the $I^{2}$ statistic. Sources of between-study heterogeneity (significant Cochrane Q test or $I^{2}>50 \%$ ) were investigated by means of stratification and meta-regression considering potential confounders when a statistically significant random effect estimate was observed, and more than five estimates were included. Dichotomous levels were defined by medians of study duration, publication year, baseline $Z$-score, sample size by comparison group and baseline age. We also considered location (studies conducted in Africa $v$. studies conducted elsewhere) and studies having different types of animalsource food supplementation.

The comparison between studies was reported by means of the p-value for the Wald coefficient of the meta-regression. Residual heterogeneity was calculated as the difference of the between-study variance with and without the covariate ${ }^{(40)}$. On the other hand, when relevant heterogeneity was found in meta-analyses based on less than five estimates stratification, study exclusion was conducted to identify it source. For the evaluation of heterogeneity by meta-regression and influence 
analyses, a study or a covariate were considered as relevantly associated with reduced heterogeneity if its contribution led to an $I^{2}$ below $50 \%$. Publication bias was assessed by visual inspection of the funnel plot and by Egger's test ${ }^{(41)}$. Sensitivity analyses were conducted by means of influence analysis, excluding one study at a time and excluding outliers in the form of the higher and lower estimates included in that specific meta-analysis. All statistical evaluations were conducted using STATA vers. 12. The METAN, METANINF, METABIAS, METAFUNNEL and METAREG functions were used to perform random effect estimates, influence analyses, publication bias assessment, funnel plot and meta-regression, respectively. All statistical tests were two-tailed and type I error rate was set at $5 \%(\alpha=0 \cdot 05)$.

\section{Results}

\section{Study selection}

Our literature search identified 1188 records plus 6 additional records from screening the references of some relevant articles. After exclusion of duplicates, we obtained 1188 records as the 6 additional records identified were duplicates. Of these, 158 were excluded because they were either systematic reviews, protocols or letters; and an additional 1006 papers were excluded because they were not related to the topic of interest. After the paper selection phase, 24 papers were assessed for eligibility and their full texts were screened. Finally, after proofreading of the full text, 14 papers were included in the qualitative synthesis, 8 of which were also included in the meta-analysis on LAZ, WAZ and WLZ $Z^{(29,30,32-34,42-44)}$. In addition, $5^{(29,32,34,43,45)}$ of the 14 papers were included in the meta-analysis on HCAZ and $2^{(30,44)}$ in the meta-analysis on BMIZ. The flow chart of paper selection is presented in Fig. 1.

\section{Study characteristics}

The 14 studies that were included in the qualitative synthesis were published in the period 2000 to 2019 with the median publication year being 2015. Among the included studies, six where from Africa $(33,34,42,43,46,47)$, four were from the American continent ${ }^{(30,31,44,45)}$ of which two were from the $\mathrm{USA}^{(31,45)}$, three were from Asia ${ }^{(32,48,49)}$ and one study had a multicentre design being done in Zambia, Guatemala and Pakistan $^{(29)}$. The age at baseline ranged between 5 and 24 months with a median of 6 months. Study duration ranged from 5 to 14 months with a median of 8 months. The total sample size by study ranged from $42^{(45)}$ to $1471^{(32)}$, with a median of 250 children. A summary of the characteristics of the included papers is presented in Table 2. The setting for all the included papers in this meta-analysis were marginal rural communities $^{(29,30,32,34,42-44,33)}$ except data collected in Guatemala and Pakistan ${ }^{(29)}$ that were based in semirural and urban areas, respectively. Majority of the studies included in the meta-analysis did not report on the background diet of the participating children. The only three studies that gave some overview of the background diet of their participating children found little or no intake of animal-source foods ${ }^{(34,43)}$ and a high intake of sugary foods, drinks and soda ${ }^{(30)}$, respectively, as presented in Supplementary Table 1.

\section{Effect of animal-source supplementation and child growth based on measures of body size}

Eight studies reported full data regarding the effect of animalbased food supplementation on LAZ and WAZ ${ }^{(29,30,32-34,42-44)}$. Five studies ${ }^{(45-49)}$ did not report age-specific $Z$-score of body size, one study reported LAZ and WAZ on a plot but numerical data were not available ${ }^{(31)}$. Fig. 2 depicts the effect sizes for the two outcome variables. Generally, studies showed a positive effect on children's growth for animal-based food supplementation in comparison with the control, except for two studies for $\mathrm{LAZ}^{(29,42)}$ and one for $\mathrm{WAZ}^{(29)}$. Heterogeneity between studies were observed to be $76.8 \%\left(P_{\text {Cochrane-Q }}<0.001\right)$ and $89.5 \%$ ( $\left.P_{\text {Cochrane-Q }}<0.001\right)$ for LAZ and WAZ, respectively. We observed a homogeneous study contribution with random effect weights ranging from 6 to $19 \%$ and 9 to $15 \%$ for LAZ and WAZ, respectively. Based on this study's statistical analysis, it was observed that animal-based food supplementation resulted in a higher LAZ and WAZ in comparison with the control group with random effect size estimates of 0.15 (95\% CI $0 \cdot 02,0 \cdot 27$ ) and $0 \cdot 20$ (95\% CI 0.03, 0.36), respectively (Fig. 2). These results are both confirmed by sensitivity analyses.

\section{Sensitivity analyses}

The random effect size estimate for LAZ conducted by excluding one study at a time ranged between 0.08 (95\% CI ( $-0.01,0.17)$; $\left.I^{2}=53.2 \% ; P_{\text {Cochrane-Q }}=0.046\right)$ and $0.19(95 \% \mathrm{CI}(0.07,0.32)$; $\left.I^{2}=71.2 \% ; P_{\text {Cochrane-Q }}=0.002\right)$, and when excluding the two most extreme results reported by Lannotti et $a l .{ }^{(30)}$ and by Krebs et al. ${ }^{(29)}$, respectively. Notably, those studies had also high risk of bias (online Supplementary Fig. S2). Furthermore, when both extreme estimates were excluded, the random effect size estimate was $0 \cdot 10(95 \%$ CI $0 \cdot 05,0 \cdot 14)$, with a null residual heterogeneity $\left(I^{2}=0 \% ; P_{\text {Cochrane-Q }}=0.447\right)$. When looking at sensitivity analyses conducted on WAZ, it was observed that the exclusion of one study at a time resulted in effect size estimates ranging from $0.11\left(95 \% \mathrm{CI}(-0.01,0.23) ; I^{2}=74.5 \%\right.$; $\left.P_{\text {Cochrane-Q }}<0.001\right)$ to 0.25 (95\% CI $(0.08,0.43) ; I^{2}=87.5 \%$; $\left.P_{\text {Cochrane-Q }}=0.001\right)$, and when excluding the studies by Lannotti et $a l .{ }^{(30)}$ and by Krebs et al. ${ }^{(29)}$, respectively. When both extreme observations were excluded, the random effect size estimate was 0.15 (95\% CI 0.04, 0.26) with a borderline relevant heterogeneity $\left(I^{2}=55.7 \%, P_{\text {Cochrane-Q }}=0.046\right)$.

\section{Effect size estimates for animal-source food consumption on measures of body size}

Among the different factors investigated in this meta-analysis, it was observed that only sample size was related to a reduction of heterogeneity. However, we observed a relevant increased effect on LAZ and WAZ when the food supplementation was based on egg. Notably, when considering studies having egg as a complementary food ${ }^{(30,33,34)}$, we reported a border-line non-statistically significant, but clinically relevant high effect size 
Records identified

by database search $(\mathrm{n}=1,188)$

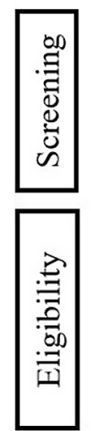

of $0.31(95 \% \mathrm{CI}-0.03,0.64)$ and $0.36(95 \% \mathrm{CI}-0.03,0.75)$ for LAZ and WAZ, respectively (Table 3).

When looking at meta-analyses stratified by considering studies in which participants were breastfed ${ }^{(29,34,42,43)}$, we observed a borderline non-statistically significant larger effect size on LAZ and WAZ for studies in which children were not breastfed. Specifically, when considering LAZ, we observed an effect size of $0.31\left(95 \% \mathrm{CI}(0.07,0.56) ; I^{2}=81.2 \%\right.$; $\left.P_{\text {Cochrane-Q }}=0.001\right)$ and an effect size of $0.0 \quad(95 \%$ CI $\left.(-0.14,0.14) ; I^{2}=54.6 \% ; P_{\text {Cochrane-Q }}=0.085\right)$ for children that were not breastfed and those who were breastfed, respectively. A similar result was observed for WAZ (effect size $=0.37,95 \%$ CI $(0.05,0.69) ; I^{2}=93.0 \% ; P_{\text {Cochrane-Q }}<0.001$ and effect size $=0.01,95 \%$ CI $(-0.13,0.14) ; I^{2}=59.4 \%$; $P_{\text {Cochrane-Q }}=0.061$, for children that were not breastfed and those who were breastfed, respectively). Finally, when considering data reported by the eight studies ${ }^{(29,30,32-34,42-44)}$, we observed an effect size of $0.05 ; 95 \% \mathrm{CI}(-0 \cdot 02,0 \cdot 12)$; $I^{2}=38.7 \% ; \quad P_{\text {Cochrane-Q }}=0.121$ for WLZ (online Supplementary Fig. S1). We also observed an effect on HCAZ, based on data from five studies ${ }^{(29,32,34,43,45)}$ (effect size $=$ $-0.02 ; 95 \%$ CI $\left.(0 \cdot 13,0 \cdot 10) ; I^{2}=70.9 \% ; P_{\text {Cochrane-Q }}=0.008\right)$ and BMIZ based on data from two studies ${ }^{(30,44)}$, (effect size $=0 \cdot 13 ; 95 \%$ CI $\left.(-0.05,0.31) ; I^{2}=0 \% ; P_{\text {Cochrane-Q }}=0.39\right)$.

\section{Bias assessment}

Moderate to high risk of bias was observed for most of the included studies (online Supplementary Fig. S2). Few studies gave a clear description of the randomisation technique and allocation concealment. However, all studies were randomised so that at least random allocation should not be a major source of bias. Blinding of participants was not possible for the included studies after enrolment as the intervention was based on food supplementation. However, group assignment was masked for the investigators and during statistical analysis. Also, the use of objectively assessed outcomes and the young age of the participants should have completely avoided a possible performance bias or a placebo effect. The studies that were included had low attrition rates, with similar attrition rates for the treatment and the control groups (Table 2); thus, attrition rate could not have influenced the results. Additionally, almost all studies reported full results for all considered outcomes and so we assume that selective reporting may have not affected our results because incomplete data were negligible. Finally, no indication for publication bias effect emerged in the current meta-analysis according to the reporting of a non-significant Egger test $\left(P_{\text {Egger }}=0.460\right.$ and $P_{\text {Egger }}=0.298$, for LAZ and WAZ, respectively) and symmetric funnel plots for all the outcomes under analysis (online Supplementary Fig. S3). 
Table 2. Qualitative synthesis, characteristics of included studies

\begin{tabular}{|c|c|c|c|c|c|c|c|}
\hline $\begin{array}{l}\text { First author } \\
\text { (year) }\end{array}$ & Country & $\begin{array}{l}\text { Baseline age } \\
\text { (months) }\end{array}$ & $\begin{array}{l}\text { Treatments under study and comparison groups con- } \\
\text { sidered for the meta-analysis }\end{array}$ & M:F ratio & $\begin{array}{l}\text { Duration } \\
\text { (months) }\end{array}$ & Sample size & $\begin{array}{l}\text { Attrition } \\
(\%)\end{array}$ \\
\hline $\begin{array}{l}\text { Beckett } \\
\quad \text { et al., } 2000\end{array}$ & Indonesia & 12 and 18 & $\begin{array}{l}\text { High energy and micronutrients } \\
\text { Micronutrient and skim milk } \\
\text { Skim milk only }\end{array}$ & $\begin{array}{l}19: 19 \\
19: 18 \\
19: 21\end{array}$ & 12 & $\begin{array}{ll} & 38 \\
37 & \\
40 & \end{array}$ & NR \\
\hline $\begin{array}{l}\text { Lin et al., } \\
2008\end{array}$ & Malawi & $5 \cdot 5-6.5$ & $\begin{array}{l}\text { Fortified soy/peanut spread } \\
\text { Fish-fortified thickened maize porridge }\end{array}$ & $\begin{array}{l}62: 63 \\
51: 64\end{array}$ & 14 & $109^{121}$ & $\begin{array}{l}15 \\
14\end{array}$ \\
\hline $\begin{array}{l}\text { Rosado } \\
\quad \text { et al. } \\
2011\end{array}$ & Mexico & $12-24$ & $\begin{array}{l}44 \mathrm{~g} \text { of oportunidades food supplement } \\
\text { †25 g of whole powdered milk } \\
\text { *Placebo formula }\end{array}$ & $\begin{array}{l}32: 27 \\
37: 27 \\
37: 26\end{array}$ & 6 & $\begin{array}{ll} & 59 \\
64 & \\
63 & \end{array}$ & $\begin{array}{l}15 \\
11 \\
12\end{array}$ \\
\hline $\begin{array}{l}\text { Krebs et al., } \\
2012\end{array}$ & $\begin{array}{l}\text { DRC } \\
\text { Zambia } \\
\text { Guatemala } \\
\text { Pakistan }\end{array}$ & 6 & $\begin{array}{l}\text { †Thirty grams of minced red meat } \\
{ }^{*} \text { Micronutrient fortified rice-soya-based cereal }\end{array}$ & $250: 282$ 270:260 & 12 & $530^{532}$ & $\begin{array}{l}86 \\
88\end{array}$ \\
\hline $\begin{array}{l}\text { Long et al., } \\
2012\end{array}$ & Kenya & $11-40$ & $\begin{array}{l}\text { †Minced beef millet-based porridge } \\
\text { Whole ultra-heat-treated milk millet-based porridge } \\
\text { *Plain millet-based porridge }\end{array}$ & $\begin{array}{l}35: 46 \\
47: 50 \\
48: 48\end{array}$ & 5 & $\begin{array}{ll} & 81 \\
97 & \\
96 & \end{array}$ & $\begin{array}{r}8 \\
11 \\
6\end{array}$ \\
\hline $\begin{array}{l}\text { Tang \& } \\
\text { Krebs, } \\
2014\end{array}$ & USA & $5-6$ & $\begin{array}{l}\text { Commercially available or pressed rice cereal product } \\
\text { Fe- and Zn-fortified cereal with whole grain iron-forti- } \\
\text { fied cereal }\end{array}$ & $17: 25$ & 4 & 28 & $\begin{array}{l}1 \\
2\end{array}$ \\
\hline $\begin{array}{l}\text { Bauserman } \\
\text { et al., } 2015\end{array}$ & DRC & 6 & $\begin{array}{l}\text { †Forty-five grams caterpillar cereal } \\
{ }^{*} \text { No intervention }\end{array}$ & $\begin{array}{l}46: 45 \\
43: 41\end{array}$ & 12 & $81 \quad 91$ & $\begin{array}{l}20 \\
27\end{array}$ \\
\hline $\begin{array}{l}\text { Skau et al., } \\
2015\end{array}$ & Cambodia & 6 & $\begin{array}{l}\text { Winfood fortified with small fish and edible spiders } \\
\text { Winfood lite fortified with small fish. } \\
\text { Purely plant-based corn-soya blend with } 8 \% \text { dried } \\
\text { skimmed milk. } \\
\text { Purely plant-based fortified corn-soya blend }\end{array}$ & $\begin{array}{l}45: 40 \\
48: 45 \\
46: 42 \\
49: 43\end{array}$ & 9 & $\begin{array}{ll} & 85 \\
93 & \\
88 & \\
92 & \end{array}$ & $\begin{array}{l}21 \\
11 \\
15 \\
14\end{array}$ \\
\hline $\begin{array}{l}\text { lannotti et al., } \\
2017\end{array}$ & Ecuador & $6-9$ & $\begin{array}{l}\dagger 1 \mathrm{egg} / \mathrm{d} \\
{ }^{*} \text { No intervention }\end{array}$ & $\begin{array}{l}45: 30 \\
30: 43\end{array}$ & 6 & $73^{75}$ & $\begin{array}{r}5 \\
10\end{array}$ \\
\hline $\begin{array}{l}\text { Tang et al., } \\
2018\end{array}$ & USA & 5 & $\begin{array}{l}\text { Minced beef millet-based porridge } \\
\text { Infant yogurt, cheese, and a powdered concentrate of } \\
80 \% \text { whey protein }\end{array}$ & $\begin{array}{l}14: 18 \\
15: 17\end{array}$ & 7 & $32 \quad 32$ & $\begin{array}{l}3 \\
4\end{array}$ \\
\hline $\begin{array}{l}\text { Konyole } \\
\quad \text { et al., } 2019\end{array}$ & Kenya & 6 & $\begin{array}{l}\text { Winfood classic } \neq \\
\text { Winfood lite§ } \\
\text { Purely plant-based fortified corn-soya blend }\end{array}$ & $\begin{array}{l}76: 65 \\
81: 69 \\
83: 54\end{array}$ & 9 & 141150137 & $\begin{array}{l}24 \\
17 \\
30\end{array}$ \\
\hline $\begin{array}{l}\text { Stewart } \\
\text { et al., } 2019\end{array}$ & Malawi & $6-9$ & $\begin{array}{l}\dagger 1 \mathrm{egg} / \mathrm{d} \\
{ }^{*} \text { No intervention }\end{array}$ & $150: 140158: 147$ & 6 & 290305 & $\begin{array}{l}41 \\
24\end{array}$ \\
\hline
\end{tabular}

DRC, Democratic Republic of Congo; M, male, F, female; NR, not reported.

${ }^{*}$ Control group.

† Comparison group.

¥ Added with germinated amaranth $(71 \%)$, maize (10.4\%), small fish (3\%) and edible termites $(10 \%)$.

$\S$ Added with germinated amaranth $(82.5 \%)$, maize $(10.2 \%)$ and multi-micronutrient premix.

Attrition: percentage of lost to follow-up at the end of the study; groups considered for the meta-analyses.

\section{Discussion}

In this meta-analysis, it was observed that animal-source foods may be a suitable complementary food to help improve growth in children between the ages of 6 and 24 months in LMICs, communities, populations and low-income households. First and foremost, it was observed that providing animalsource foods as part of the complementary diet resulted in an increase in LAZ and WAZ values, compared with the comparison groups. The estimated effect size of 0.15 and 0.20 units for LAZ and WAZ, respectively, will correspond to a biologically relevant effect size, considering that we observed standard deviation ranging from 0.5 to 1.4 and 0.6 to 1.4 for LAZ and WAZ, respectively ${ }^{(32,42)}$.

Furthermore, it was observed in this meta-analysis that children who are not breastfed might benefit from the intake of animal-source foods, compared with those that are breastfed. It is well acknowledged that the complementary feeding should be started immediately after the recommended 6 months of exclusive breast-feeding to alleviate growth faltering. Thus, children who did not benefit from the recommended 6-month period of breast-feeding may benefit from animal-source foods such as meat, eggs and milk when added to their usual diets to meet their needs for nutrients such as protein, $\mathrm{Zn}$ and $\mathrm{Fe}^{(50)}$. It is true that there are concerns about some potential negative health consequences such as obesity, excessive intake of saturated fats, heart diseases, high blood pressure, type 2 diabetes, poor kidney function and prostate when people including children, particularly those from resource-rich environments, populations and wealthier households overindulge animal-source foods ${ }^{(51-55)}$. One cannot however disregard the potential benefits of the consumption of the same animal-source foods among children from LMICs, communities, populations and poor households who are susceptible to undernutrition 


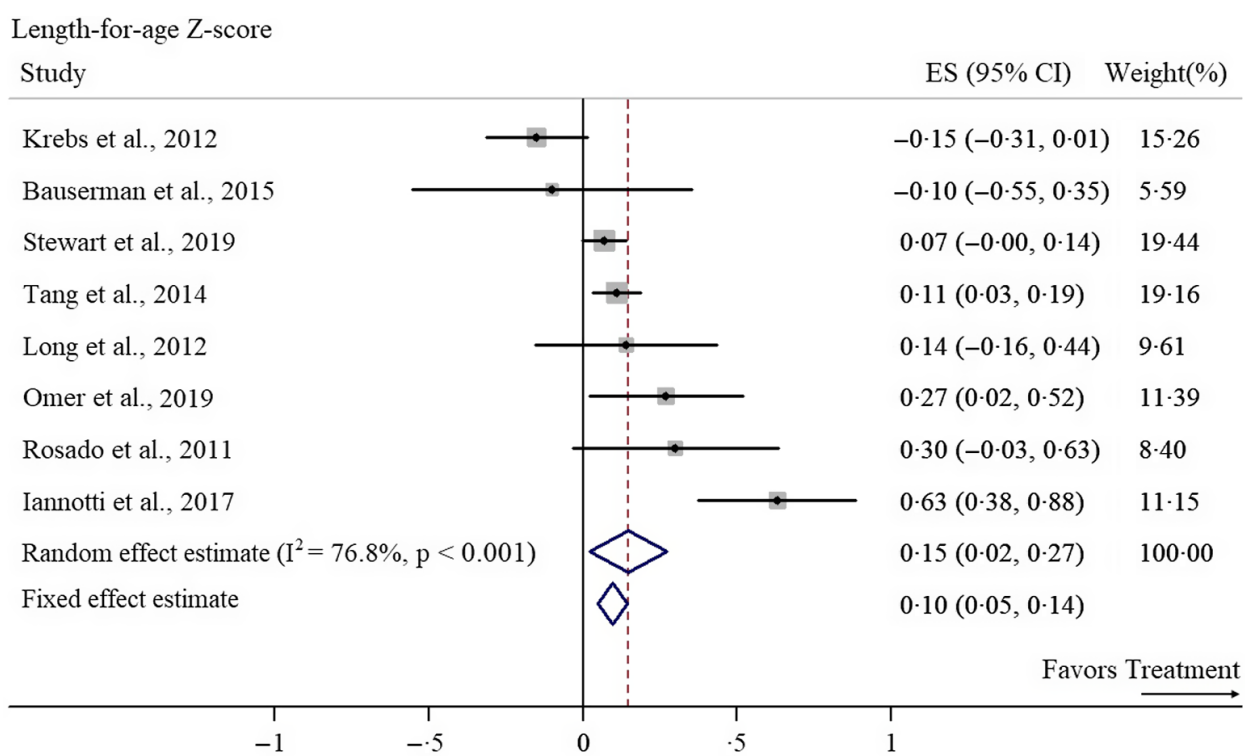

Weight-for-age Z-score

\begin{tabular}{|c|c|c|c|}
\hline Study & & $\mathrm{ES}(95 \% \mathrm{CI}) \quad \mathrm{V}$ & Weight $(\%)$ \\
\hline Krebs et al., 2012 & & $-0.13(-0.25,-0.01)$ & $14 \cdot 52$ \\
\hline Long et al., 2012 & & $0.06(-0.19,0 \cdot 31)$ & $11 \cdot 51$ \\
\hline Stewart et al., 2019 & & $0.06(-0 \cdot 04,0 \cdot 16)$ & $14 \cdot 82$ \\
\hline Tang et al., 2014 & & $0.08(0.01,0.15)$ & $15 \cdot 26$ \\
\hline Bauserman et al., 2015 & & $0.20(-0.17,0.57)$ & $8 \cdot 80$ \\
\hline Rosado et al., 2011 & & $0.40(0.08,0.72)$ & $9 \cdot 88$ \\
\hline Omer et al., 2019 & & $0 \cdot 43(0 \cdot 18,0 \cdot 68)$ & $11 \cdot 46$ \\
\hline Iannotti et al., 2017 & $\longrightarrow$ & $0.61(0.45,0.77)$ & $13 \cdot 73$ \\
\hline Random effect estimate $\left(\mathrm{I}^{2}=89.5 \%, \mathrm{p}<0.001\right)$ & & $0.20(0.03,0.36)$ & $100 \cdot 00$ \\
\hline Fixed effect estimate & & $0.11(0.06,0.15)$ & \\
\hline & & \multicolumn{2}{|c|}{ Favors Treatment } \\
\hline $\begin{array}{c}1 \\
-.5\end{array}$ & $\begin{array}{l}1 \\
.5\end{array}$ & 1 & \\
\hline
\end{tabular}

Fig. 2. Meta-analyses of length-for-age $Z$-score and weight-for-age $Z$-score comparing animal-source food supplementation $v$. control.

during complementary feeding ${ }^{(15,56,57)}$. The excessive intake of animal-source foods such as meat, eggs and milk by children from high-income countries, communities, populations and wealthier households should not be the basis for policymakers to put limitations on its consumption among children from LMICs, communities, populations and poorer households who could benefit nutritionally from its consumption during complementary feeding to improve their nutrition and health status ${ }^{(58-63)}$.

The strength of our results was also limited by quite a substantial heterogeneity between studies. Notably, between-study heterogeneity was observed due to the study by Krebs et $a l .{ }^{(29)}$ and Lannotti et $a l .{ }^{(30)}$. Krebs et al. ${ }^{(29)}$ conducted a multicentre study in 1062 children in Congo, Zambia, Guatemala and Pakistan; comparing the effect of meat $v$. cereal fortified with multiple micronutrients. Not only did their study obtain the lowest effect size compared with the other studies included in this meta-analysis, but they also reported a negative effect size for both LAZ and WAZ. A plausible explanation for this observed outcome might be due to the influence of environmental-related factors. Importantly, children living in settings with poor sanitation and hygiene conditions may ingest faecal bacterial through contaminated foods, drinking water and through the surrounding, and this may cause environmental enteric dysfunction. Environmental enteric dysfunction increases intestinal inflammation leading to reduces intestinal absorption of nutrients and this may cause growth faltering during nutritional interventions in children ${ }^{(64,65)}$. Also, Krebs et al. ${ }^{(29)}$ did not report an improved growth in children, irrespective of the treatment, with the end line mean $Z$-score being lower than the baseline mean $Z$-score. A plausible explanation for this finding is the poor growth status at baseline (mean $Z$-score of -1.38 (sD 1.36) and 
Table 3. Stratification and meta-regression analyses

(Mean values and $95 \%$ confidence intervals)

\begin{tabular}{|c|c|c|c|c|c|c|c|c|}
\hline & \multicolumn{3}{|c|}{ Yes } & \multicolumn{3}{|c|}{ No } & \multicolumn{2}{|c|}{ Comparison } \\
\hline & Effect size & $95 \% \mathrm{Cl}$ & $\mathrm{I}^{2}(\%)$ & Effect size & $95 \% \mathrm{Cl}$ & $I^{2}(\%)$ & $\mathrm{P}$ & $\mathrm{I}^{2}{ }_{\text {Res. }}(\%)$ \\
\hline \multicolumn{9}{|l|}{ Length-for-age $Z$-score } \\
\hline Duration $<8.5$ months & 0.13 & $0.02,0.24$ & 23.5 & 0.13 & $-0.15,0.41$ & 88.6 & 0.778 & $80 \cdot 1$ \\
\hline Publication year < 2015 & 0.07 & $-0.10,0.24$ & $69 \cdot 6$ & 0.23 & $-0.05,0.52$ & 84.7 & 0.408 & $79 \cdot 7$ \\
\hline Based in Africa & 0.09 & $0.01,0.16$ & $2 \cdot 20$ & 0.20 & $-0.07,0.47$ & $88 \cdot 8$ & 0.650 & 79.9 \\
\hline Baseline $L A Z<-1.4$ & 0.27 & $-0.01,0.55$ & $71 \cdot 6$ & 0.06 & $-0.05,0.16$ & $69 \cdot 0$ & 0.231 & $70 \cdot 4$ \\
\hline Sample size group $<100$ & 0.04 & $-0.077,0.14$ & 74.5 & 0.28 & $0.06,0.50$ & $62 \cdot 2$ & 0.112 & 67.4 \\
\hline Baseline age $<7.5$ months & 0.12 & $-0.16,0.39$ & 88.4 & 0.13 & $0.06,0.20$ & 0.00 & 0.678 & 78.9 \\
\hline Egg supplementation & 0.31 & $-0.03,0.64$ & $89 \cdot 3$ & 0.05 & $-0.10,0.21$ & $61 \cdot 7$ & 0.200 & 79.4 \\
\hline Breast-feeding & 0.00 & $-0.14,0.14$ & $54 \cdot 6$ & 0.31 & $0.07,0.56$ & $81 \cdot 2$ & 0.073 & $77 \cdot 4$ \\
\hline \multicolumn{9}{|l|}{ Weight-for-age $Z$-score } \\
\hline Duration $<8.5$ months & 0.21 & $0.01,0.41$ & $71 \cdot 0$ & 0.18 & $-0.11,0.48$ & 94.6 & 0.848 & 91.0 \\
\hline Publication year $<2015$ & 0.06 & $-0.11,0.23$ & $78 \cdot 9$ & 0.33 & $0.00,0.65$ & 91.7 & 0.189 & $88 \cdot 1$ \\
\hline Based in Africa & 0.23 & $-0.07,0.52$ & 94.9 & 0.17 & $-0.01,0.34$ & $60 \cdot 1$ & 0.829 & 91.0 \\
\hline Baseline WAZ $<-0.8$ & 0.12 & $-0.15,0.40$ & $82 \cdot 5$ & 0.27 & $0.04,0.51$ & 92.9 & 0.457 & 89.9 \\
\hline Sample size group $<100$ & 0.01 & $-0.11,0.13$ & $78 \cdot 8$ & 0.35 & $0.13,0.58$ & 73.5 & 0.035 & $75 \cdot 6$ \\
\hline Baseline age $<7.5$ months & 0.18 & $-0.14,0.50$ & 94.7 & 0.21 & $0.02,0.41$ & $70 \cdot 7$ & 0.811 & 91.0 \\
\hline Egg supplementation & 0.36 & $-0.03,0.75$ & 94.4 & 0.07 & $-0.08,0.23$ & $73 \cdot 2$ & 0.183 & $88 \cdot 2$ \\
\hline Breast-feeding & 0.01 & $-0.13,0.14$ & $59 \cdot 4$ & 0.37 & $0.05,0.69$ & 93.0 & 0.064 & 87.9 \\
\hline
\end{tabular}

LAZ, length-for-age $Z$-score; WAZ, weight-for-age $Z$-score.

-0.96 (SD 1.31) for LAZ and WAZ, respectively), for which animal-source foods alone was not sufficient to achieve a better growth outcome compared with the fortified cereal. It is also reasonable to assume that the finding of Krebs et al. ${ }^{(29)}$ could be ascribed, at least partly, to the high micronutrient content of the fortified cereal, as nutrients needed for growth, such as Fe, $\mathrm{Cu}, \mathrm{Se}, \mathrm{Mg}$, niacin, biotin and folate were more concentrated in the fortified cereal compared with the meat ${ }^{(66)}$, or a possible reverse causation due to the high undernutrition prevalence of the participants. The study of Lannotti et al. ${ }^{(30)}$, on the other hand, compared egg supplementation to no-intervention in 160 children in Ecuador. They reported a larger effect on growth in children receiving egg compared with those not receiving any food supplementation. In their study, a high mean $Z$-score of undernutrition was also observed at baseline for LAZ ( -1.9 (SD 1.0) and WAZ (-0.65 (SD 1.1)). We therefore assume that the heterogeneity observed in this meta-analysis was due to the type of supplementation for the comparison group.

It was further observed in this meta-analysis that giving egg to the treatment group could result in a higher LAZ and WAZ increase compared with the control. Most importantly, the three studies based on egg supplementation ${ }^{(30,33,34)}$ had a pooled effect size of 0.31 and 0.36 for LAZ and WAZ, respectively, over the 6-month intervention period. These three studies however had no intervention as control, which could have affected the magnitude of the effect size observed. The motivation for looking specifically at the effect of providing egg on child growth was that eggs were previously not considered an acceptable food for infants aged 6 months because of possible allergy, but this view has changed, and egg is now included in the guidelines for infants and young child feeding ${ }^{(5,50)}$. Additionally, the American dietary guidelines advisory group recently recommended eggs as a first complementary food for infants and very young children ${ }^{(67)}$. Eggs are also indicated as complementary food from 6 months in many LMICs' dietary guidelines for children including the South African dietary guidelines for mothers ${ }^{(68)}$.

A possible explanation to why eggs might have impacted on the growth of children is that egg represents a balanced food of higher biological value compared with any other animal-based food. Egg is one of the most valuable components of the human $\operatorname{diet}^{(69,70)}$. For instance, the amino acids leucine and glutamine found in egg appears to play a role in the regulation of the mTORC1 activation pathway for muscle cell growth, by regulating skeletal muscle protein synthesis ${ }^{(71)}$. Leucine is an essential amino acid that can only be obtained from the diet, and it is especially very high in foods of animal origin such as the $\mathrm{egg}^{(70)}$. In comparison with other animal-source foods, egg has a high leucine content per calorie. It is also nutritionally dense in proteins and other essential micronutrients such as choline ${ }^{(72)}$. Choline is needed in the body for cellular maintenance and growth throughout the life cycle. Although choline can be synthesised endogenously by the body, it is not enough to meet the human body's requirement, and thus must be obtained from food sources $^{(73)}$. One large egg contains approximately $150 \mathrm{mg}$ of choline $v$. the daily requirement for infants of $125 \mathrm{mg}$ at the age of 6 months, and $150 \mathrm{mg}$ at the age of 7 to 12 months ${ }^{(74)}$. Eggs also contain healthy fats such as phospholipids and PUFA needed for growth of infants and young children ${ }^{(16)}$. It has thus been argued that due to its high leucine, choline and protein content, egg can be used as an early food source to help overcome the nutritional deficiencies in the usual complementary diets and ultimately alleviate growth faltering ${ }^{(72,35)}$.

The current study has numerous strong points. First, we conducted a rigorous meta-analysis of randomised control trials, which actually represents the stronger form of scientific evidence ${ }^{(75)}$. Moreover, we adopted a commonly accepted approach to scientific evidence synthesis following the most updated evidence accumulated so far. We conducted numerous stratifications and sensitivity analyses showing the robustness of 
the current results. Finally, we focused on commonly accepted standardised measures of growth considering age- and sexstandardised $Z$-score calculated according to the WHO Child Growth Standards; therefore, biases due to children's age, sex or ethnicity can be considered as negligible, making our results generalisable.

Our work has also certain limitations. Firstly, our research was limited because of the low number of studies reporting outcomes on physical growth, such as HCAZ and BMIZ. There were also limited studies reporting on egg as the treatment group. Thus, a low number of studies could have resulted in several false-negative results. Secondly, we may also consider the great variability of the study characteristics as a possible limitation. For example, baseline nutritional status varied between samples with high prevalence of undernutrition to samples with low prevalence of undernutrition. On the other hand, according to the results of this study, we may assume that an improved intake of animal protein would result in a further overall growth enhancement of children where undernutrition prevalence is higher. Also, due to the limited number of available randomised controlled studies, we had to include studies with a certain age variability, while focusing on a more limited age range between 6 and 12 months would have been preferable. Furthermore, although we only considered the effect of animal-source foods on children's growth in this meta-analysis, it is possible that the growth of the children may have been influenced by other environmental and social factors such as maternal depression and poor sanitation and hygiene. We acknowledge that plant-based foods may represent an appropriate alternative to animal-based food. Specifically, we are aware of the health-related risks of the excessive intake of animal-source foods and in particularly, the long-term risks of creating taste preferences high in saturated fat and high cholesterol foods that could results in CVD such as heart attacks and stroke during adulthood ${ }^{(76,77)}$. Nevertheless, it is well documented that there are still some children who are susceptible to growth faltering and poor health if their usual diet does not include foods from animal origin. Also, the high protein content of animal-source foods is very important for growing children aged 6 to 24 months which is the first 1, 000 $\mathrm{d}$ of life where children especially those from disadvantage settings, communities and poor households are exposed to suboptimal growth due to the lack of intake of foods from animal origin in their usual diets ${ }^{(14,23)}$.

Finally, we cannot exclude that the limited number of available randomised controlled studies may have resulted in several false-negative results.

\section{Conclusions}

In conclusion, animal-source foods may be a suitable complementary food to help improve growth in 6 to 24 months children from LMIC, communities, populations and poor households, especially if based on eggs. Furthermore, we can speculate that the important role of micronutrients to enhance and support appropriate child growth was reinforced by our research. Our results agree with a growing body of evidence showing that livestock ownership may be related to children's growth, a factor that should be further investigated by dedicated randomised controlled trial and implementation studies ${ }^{(78,79)}$.

There is a paucity of randomised controlled studies aimed at evaluating the effectiveness of the provision of animal-source foods as a complementary diet to support optimal growth in 6 to 24 months children. Therefore, it is important that in future studies, the battery of outcomes measures would be extended to other biometric outcomes of great interest, such as HCAZ and BMIZ. Additionally, it would be very beneficial if more highquality randomised controlled studies would be conducted on specific target communities and populations, such as those with high undernutrition prevalence and maybe not high-income countries, communities and populations with no food scarcity and full access to fortified baby foods and supplements.

\section{Acknowledgements}

A sincere thank you to all the authors for making this work possible.

This study received no specific grant from any funding agency, commercial or not-for-profit sectors.

H. A. and C. R. were involved in the conptualization, data curation and writing the original draft of the manuscript. H. A. performed the qualitative synthesis. C. R. performed the formal statistical analyses. A. R. defined the literature search strategy and performed the search strings. A. R., M. F. and C. M. S. review and edited the first version of the manuscript. M. F., C. M. S. and C. R. equally contributed in supervising the esearch team. All the authors actively contributed to the writing, reviewing and editing of the manuscript.

None of the authors has any conflict of interest to declare.

\section{Supplementary material}

For supplementary material/s referred to in this article, please visit https://doi.org/10.1017/S0007114522000290

\section{References}

1. WHO (2010) Nutrition Landscape Information System: Country Profile Indicators. Interpretation Guide. https://www.who. int/nutrition/nlis_interpretation_guide.pdf (accessed August 2020).

2. UNICEF, WHO \& World Bank (2020) Joint Child Malnutrition Estimates: Levels and Trends in Child Malnutrition: Key Findings of the 2020 Edition. https://www.who.int/ publications/i/item/jme-2020-edition (accessed June 2020).

3. Black RE, Victora CG, Walker SP, et al. (2013) Maternal and child undernutrition and overweight in low-income and middle-income countries. Lancet 382, 427-451.

4. Food and Agricultural Organization (2013) State of Food and Agriculture 2013: Food Systems for Better Nutrition. http:// www.fao.org/3/i3301e/i3301e.pdf (accessed June 2020).

5. WHO (2003) Guiding Principles for Complementary Feeding of the Breastfed Child. http://iris.paho.org/xmlui/handle/ 123456789/752 (accessed June 2020).

6. Abeshu MA, Lelisa A \& Geleta B (2016) Complementary feeding: review of recommendations, feeding practices, and adequacy of homemade complementary food preparations in developing countries-lessons from Ethiopia. Front Nutr 3, 41. 
7. Du Plessis LM, Kruger H \& Sweet L (2013) Complementary feeding: a critical window of opportunity from 6 months onwards. S Afr J Clin Nutr 26, S129-S140.

8. Heidkamp RA (2017) Evidence for the effects of complementary feeding interventions on the growth of infants and young children in low-and middle-income countries. Nestle Nutr Inst Workshop Ser 87, 89-102.

9. White JM, Bégin F, Kumapley R, et al. (2017) Complementary feeding practices: current global and regional estimates. Matern Child Nutr 13, e12505.

10. Dewey KG \& Adu-Afarwuah S (2008) Systematic review of the efficacy and effectiveness of complementary feeding interventions in developing countries. Matern Child Nutr 4, 24-85.

11. Onyango AW, Borghi $\mathrm{E}$, de Onis $\mathrm{M}$, et al. (2014) Complementary feeding and attained linear growth among 6-23-month-old children. Public Health Nutr 17, 1975-1983.

12. Iannotti $L$ (2018) The benefits of animal products for child nutrition in developing countries. Rev Sci Tech 37, 37-46.

13. Headey D, Hirvonen K \& Hoddinott J (2018) Animal sourced foods and child stunting. Am J Agric Econ 100, 1302-1319.

14. Eaton JC, Rothpletz-Puglia P, Dreker MR, et al. (2019) Effectiveness of provision of animal-source foods for supporting optimal growth and development in children 6 to 59 months of age. Cochrane Database Syst Rev 2, 1-56.

15. Grace D, Dominguez-Salas P, Alonso S, et al. (2021) The Influence of Livestock-Derived Foods on Nutrition during the First 1,000 d of Life. https://www.researchgate.net/publication/ 347309221_Complementary_feeding_practices_in_80_low-_and_ middle-income_countries_prevalence_and_socioeconomic_ inequalities_in_dietary_diversity_meal_frequency_and_dietary_ adequacy (accessed December 2021).

16. Michaelsen KF, Dewey KG, Perez-Exposito AB, et al. (2011) Food sources and intake of $n-6$ and $n-3$ fatty acids in lowincome countries with emphasis on infants, young children (6-24 months), and pregnant and lactating women. Matern Child Nutr 7, 124-140.

17. Agostoni C, Decsi T, Fewtrell M, et al. (2008) Complementary feeding: a commentary by the ESPGHAN committee on nutrition. J Pediatr Gastroenterol Nutr 46, 99-110.

18. Sutter DO \& Bender N (2021) Nutrient status and growth in vegan children. Nutr Res $\mathbf{9 1}, 13-25$.

19. Varijakshapanicker P, Mckune S, Miller L, et al. (2019) Sustainable livestock systems to improve human health, nutrition, and economic status. Anim Front 9, 39-50.

20. White R \& Hall M (2018) Environmental and nutritional implications of agriculture without animals. J Anim Sci 96, Suppl. 3 , $164-165$.

21. Sobiecki JG, Appleby PN, Bradbury KE, et al. (2016) High compliance with dietary recommendations in a cohort of meat eaters, fish eaters, vegetarians, and vegans: results from the European prospective investigation into cancer and nutrition-Oxford study. Nutr Res 36, 464-477.

22. Louwman MW, van Dusseldorp M, van de Vijver FJ, et al. (2000) Signs of impaired cognitive function in adolescents with marginal cobalamin status. Am J Clin Nutr 72, 762-769.

23. Alonso S, Dominguez-Salas P \& Grace D (2019) The role of livestock products for nutrition in the first $1,000 \mathrm{~d}$ of life. Anim Front 9, 24-31.

24. Dasi T, Selvaraj K, Pullakhandam R, et al. (2019) Animal source foods for the alleviation of double burden of malnutrition in countries undergoing nutrition transition. Anim Front 9, 32-38.

25. Tang M (2019) The impact of complementary feeding foods of animal origin on growth and the risk of overweight in infants. Anim Front 9, 5-11.

26. Semba RD (2016) The rise and fall of protein malnutrition in global health. Ann Nutr Metab 69, 79-88.
27. Dror DK \& Allen LH (2011) The importance of milk and other animal-source foods for children in low-income countries. Food Nutr Bull 32, 227-243.

28. He M, Yang Y-X, Han H, et al. (2005) Effects of yogurt supplementation on the growth of preschool children in Beijing suburbs. Biomed Environ Sci 18, 192-197.

29. Krebs NF, Mazariegos M, Chomba E, et al. (2012) Randomized controlled trial of meat compared with multimicronutrient-fortified cereal in infants and toddlers with high stunting rates in diverse settings. Am J Clin Nutr 96, 840-847.

30. Lannotti LL, Lutter CK, Stewart CP, et al. Eggs in early complementary feeding and child growth: a randomized controlled trial. Pediatrics 140, e20163459.

31. Tang M \& Krebs NF (2014) High protein intake from meat as complementary food increases growth but not adiposity in breastfed infants: a randomized trial. Am J Clin Nutr 100, 1322-1328.

32. Tang M, Sheng X-Y, Krebs NF, et al. (2014) Meat as complementary food for older breastfed infants and toddlers: a randomized, controlled trial in rural China. Food Nutr Bull 35 , Suppl. 3, S188-S192.

33. Omer A, Mulualem D, Classen H, et al. (2019) Promotion of egg and eggshell powder consumption on the nutritional status of young children in Ethiopia. Int J Food Sci Nutr Res 1, 1004

34. Stewart CP, Caswell B, Lannotti L, et al. (2019) The effect of eggs on early child growth in rural Malawi: the Mazira project randomized controlled trial. Am J Clin Nutr 110, 1026-1033.

35. Lannotti LL, Lutter CK, Bunn DA, et al. (2014) Eggs: the uncracked potential for improving maternal and young child nutrition among the world's poor. Nutr Rev 72, 355-368.

36. Shapiro MJ, Downs SM, Swartz HJ, et al. (2019) A systematic review investigating the relation between animal-source food consumption and stunting in children aged 6-60 months in low and middle-income countries. Adv Nutr 10, 827-847.

37. Cooper C, Booth A, Varley-Campbell J, et al. (2018) Defining the process to literature searching in systematic reviews: a literature review of guidance and supporting studies. BMC Med Res Methodol 18, 85.

38. Petticrew M (2015) Time to rethink the systematic review catechism? Moving from 'what works' to 'what happens. Syst $\operatorname{Rev} \mathbf{4}, 36$

39. Liberati A, Altman DG, Tetzlaff J, et al. (2009) The PRISMA statement for reporting systematic reviews and meta-analyses of studies that evaluate health care interventions: explanation and elaboration. J Clin Epidemiol 62, e1-e34.

40. Thompson SG \& Higgins JP (2002) How should meta-regression analyses be undertaken and interpreted? Stat Med 21, 1559-1573

41. Egger M, Smith GD, Schneider M, et al. (1997) Bias in metaanalysis detected by a simple, graphical test. BJM 315, 629-634.

42. Bauserman M, Lokangaka A, Gado J, et al. (2015) A cluster-randomized trial determining the efficacy of caterpillar cereal as a locally available and sustainable complementary food to prevent stunting and anaemia. Public Health Nutr 18, 1785-1792.

43. Long JK, Murphy SP, Weiss RE, et al. (2012) Meat and milk intakes and toddler growth: a comparison feeding intervention of animalsource foods in rural Kenya. Public Health Nutr 15, 1100-1107.

44. Rosado JL, López P, García OP, et al. (2011) Effectiveness of the nutritional supplement used in the Mexican Oportunidades programme on growth, anaemia, morbidity and cognitive development in children aged 12-24 months. Public Health Nutr 14, 931-937.

45. Tang M, Hendricks AE \& Krebs NF (2018) A meat- or dairybased complementary diet leads to distinct growth patterns in formula-fed infants: a randomized controlled trial. Am J Clin Nutr 107, 734-742. 
46. Lin CA, Manary MJ, Maleta K, et al. (2008) An energy-dense complementary Food Is associated with a modest increase in weight gain when compared with a fortified porridge in Malawian children aged 6-18 months. J Nutr 138, 593-598.

47. Konyole SO, Omollo SA, Kinyuru JN, et al. (2019) Effect of locally produced complementary foods on fat-free mass, linear growth, and iron status among Kenyan infants: a randomized controlled trial. Matern Child Nutr 15, e12836

48. Skau JK, Touch B, Chhoun C, et al. (2015) Effects of animal source food and micronutrient fortification in complementary food products on body composition, iron status, and linear growth: a randomized trial in Cambodia. Am J Clin Nutr 101, 742-751.

49. Beckett C, Durnin JVGA, Aitchison TC, et al. (2000) Effects of an energy and micronutrient supplement on anthropometry in undernourished children in Indonesia. Eur J Clin Nutr $\mathbf{5 4}$, Suppl. 2, S52-S59.

50. WHO (2005) Guiding Principles for Feeding Non-Breastfed Children 6-24 Months of Age. https://apps.who.int/iris/ bitstream/handle/10665/43281/9241593431.pdf?sequence=1 (accessed May 2020).

51. MacDonald J, Brevard PB, Lee RE, et al. (2009) Link between diet and cardiovascular disease in Latin America and the Caribbean using geographic information systems. Rev Panam Salud Publica 26, 290-298.

52. Moussavi N, Gavino V \& Receveur O (2008) Is obesity related to the type of dietary fatty acids? An ecological study. Public Health Nutr 11, 1149-1155.

53. Siegel KR, Echouffo-Tcheugui JB, Ali MK, et al. (2012) Societal correlates of diabetes prevalence: an analysis across 94 countries. Diabetes Res Clin Pract 96, 76-83.

54. Tang M, Dewey KG \& Krebs NF (2018) The Biology of the First $1,000 d$, 3rd ed. NW: CRC Press.

55. World Cancer Research Fund \& American Institute for Cancer Research (2022) Food, Nutrition, Physical Activity and the Prevention of Cancer - A Global Perspective. A Summary of the Third Expect Report. https://www.wcrf.org/wp-content/ uploads/2021/02/Summary-of-Third-Expert-Report-2018.pdf (accessed January 2022).

56. Fewtrell M, Bronsky J, Campoy C, et al. (2017) Complementary feeding: a position paper by the European society for paediatric gastroenterology, hepatology, and nutrition (ESPGHAN) committee on nutrition. J Pediatr Gastroenterol Nutr 64, 119-132.

57. World Health Organization (2019) Guiding Principles for Complementary Feeding of the Breastfed Child. Pan American Health. http://iris.paho.org/xmlui/handle/123456789/752 (accessed March 2019).

58. Allen LH (2008) Causes of vitamin $\mathrm{B}_{12}$ and folate deficiency. Food Nutr Bull 29, Suppl. 1, S20-S34.

59. Dror DK \& Allen LH (2008) Effect of vitamin $B_{12}$ deficiency on neurodevelopment in infants: current knowledge and possible mechanisms. Nutr Rev 66, 250-255.

60. Gupta S (2016) Brain food: clever eating. Nature 531, S12-S13.

61. Randolph TF, Schelling E, Grace D, et al. (2007) Invited review: role of livestock in human nutrition and health for poverty reduction in developing countries. J Anim Sci 85, 2788-2800.
62. Semba RD, Shardell M, Sakr Ashour FA, et al. (2016) Child stunting is associated with low circulating essential amino acids. EBioMedicine 6, 246-252.

63. Wu G (2016) Dietary protein intake and human health. Food Funct 7, 1251-1265.

64. Budge S, Parker AH, Hutchings PT, et al. (2019) Environmental enteric dysfunction and child stunting. Nutr Rev 77, 240-253.

65. Syed S, Ali A \& Duggan C (2016) Environmental enteric dysfunction in children. J Pediatr Gastroenterol Nutr 63, 6-14.

66. Krebs NF, Hambidge KM, Mazariegos M, et al. (2011) Complementary feeding: a global network cluster randomized controlled trial. BMC Pediatr 11, 4 .

67. Rubin M (2020) U.S. Dietary Guidelines Advisory Committee Recommends Eggs as a First Food for Babies and Toddlers. https://www.prnewswire.com/news-releases/us-dietaryguidelines-advisory-committee-recommends-eggs-as-a-firstfood-for-babies-and-toddlers-301094428.html?MessageRun DetailID=3020101327\&PostID=17348993\&utm_medium= email\&utm_source=rasa_io (accessed August 2020).

68. Department of Health (2018) Road to Health Booklet. https:// www.google.com $/$ search?newwindow $=1 \&$ safe $=$ active $\& r l z=$ 1C1CHBD_enZA826ZA826\&q =new + road + to + health + booklet + 2018\&sa=X\&ved=2ahUKEwiDu6HKiq_jAhW7UBUIHZMzCp0 Q1QIoAnoECAOQAw\&biw=1691\&bih=729\&dpr=1.13 (accessed July 2019).

69. Fevold HL (1951) Egg proteins. Adv Protein Chem 6, 187-252.

70. Réhault-Godbert S, Guyot N \& Nys Y (2019) The golden egg: nutritional value, bioactivities, and emerging benefits for human health. Nutrients 11, 684.

71. Jewell JL, Chul KY, Russell RC, et al. (2015) Metabolism. Differential regulation of mTORC1 by leucine and glutamine. Science 347, 194-198.

72. Egg Nutrition Centre (2014) Leucine: Promoting Muscle Anabolism at Breakfast. https://www.eggnutritioncenter.org/ topics/physical-performance/page/3/\#: :text=Eggs\%20contain $\% 201.086 \mathrm{~g} \% 20$ of,cheese\%20(see\%20figure\%20below) (accessed August 2020).

73. Wiedeman AM, Barr SI, Green TJ, et al. (2018) Dietary choline intake: current state of knowledge across the life cycle. Nutrients 10, 1513

74. Hayes K (2020) Choline throughout the Kife-Span. https:// www.incredibleegg.org/nutrition/articles/choline-throughoutthe-life-span/ (accessed August 2020).

75. West S, King V, Lohr KN, et al. (2002) Systems to Rate the Strength of Scientific Evidence: Summary. https://www.ncbi. nlm.nih.gov/books/NBK11930/ (accessed August 2020).

76. Melina V, Craig W \& Levin S (2016) Position of the academy of nutrition and dietetics: vegetarian diets. J Acad Nutr Diet 116, 1970-1980.

77. Tonstad S, Butler T, Yan R, et al. (2009) Type of vegetarian diet, body weight, and prevalence of type 2 diabetes. Diabetes Care 32, 791-796.

78. Dumas SE, Kassa L, Young SL, et al. (2018) Examining the association between livestock ownership typologies and child nutrition in the Luangwa Valley, Zambia. PLOS ONE 13, e0191339.

79. Mosites EM, Rabinowitz PM, Thumbi SM, et al. (2015) The relationship between livestock ownership and child stunting in three countries in Eastern Africa using national survey data. PLOS ONE 10, e0136686. 